\title{
Patterns of Statin Use and Long-term Adherence and Persistence among Older Adults with
}

\section{Diabetes}

Running title: Statin use in older Australians with diabetes.

Richard OFORI-ASENSO ${ }^{1,2,3}$; Jenni LLOMÄKI ${ }^{4,5}$; Mark TACEY ${ }^{1}$; Ella ZOMER ${ }^{1}$; Andrea J

CURTIS $^{3}$; J Simon BELL ${ }^{4,5,6}$; Sophia ZOUNGAS ${ }^{3}$; Danny LIEW ${ }^{1 *}$

${ }^{1}$ Centre of Cardiovascular Research and Education in Therapeutics, Department of Epidemiology and Preventive Medicine, Monash University, Melbourne, Australia;

${ }^{2}$ Epidemiological Modelling Unit, Department of Epidemiology and Preventive Medicine, Monash University, Melbourne, Australia

${ }^{3}$ Division of Metabolism, Ageing and Genomics, Department of Epidemiology and Preventive Medicine, Monash University, Melbourne, Australia.

${ }^{4}$ Centre for Medicine Use and Safety, Faculty of Pharmacy and Pharmaceutical Science, Monash University, Melbourne, Australia.

${ }^{5}$ Department of Epidemiology and Preventive Medicine, Monash University, Melbourne, Australia.

${ }^{6}$ School of Pharmacy and Medical Sciences, University of South Australia, Adelaide, Australia.

\section{*Correspondence to:}

Professor Danny Liew

Department of Epidemiology and Preventive Medicine

Monash University

99 Commercial Road,

'Melbourne, Australia

VIC 3004

Tel: $+61-3990-30759$

danny.liew@monash.edu

This is the author manuscript accepted for publication and has undergone full peer review but has not been through the copyediting, typesetting, pagination and proofreading process, which may lead to differences between this version and the Version of Record. Please cite this article as doi: 10.1111/1753-0407.12769

This article is protected by copyright. All rights reserved. 
Word count (main text): 3154

Number of figures: 2

Number of tables: 1

\begin{abstract}
Background: Statins reduce the risk of cardiovascular disease in patients with diabetes. We examined the prevalence of statin use and assessed the long-term adherence and persistence among people aged $\geq 65$ years with diabetes.
\end{abstract}

Methods: Pharmaceutical Benefits Scheme data covering a 10\% random sample of the Australian population were analysed. Among older adults with diabetes, the yearly prevalence of statin use was compared via Poisson regression modelling using 2006 as the reference year. A cohort of 7,400 new statin users (mean age 72.9 years; female $46.2 \%$ ) was followed longitudinally. Adherence was assessed via the proportion of days covered (PDC). Statin discontinuation was defined as the first $\geq 90$ days without statin coverage.

Results: The prevalence of statin use increased from $52.0 \%$ in 2006 to $71.2 \%$ in 2016 (age-and-sexadjusted rate ratio [aRR] 1.37, 95\% CI 1.33-1.41). No gender differences in statin use was observed, but the likelihood of being dispensed statin decreased with increasing age. Among the longitudinal cohort, the proportion adherent ( $\mathrm{PDC} \geq 0.80$ ) decreased from $54.0 \%$ at 6 months to $37.0 \%$ at 9 years. Over a mean follow-up of 4.9 years, $66.8 \%$ discontinued, including $42.7 \%$ who stopped their statin within the first year. No age or gender differences in statin discontinuation were evident.

Conclusions: Statin use has increased among older adults with diabetes. However, adherence is low and discontinuation is high. Further investigations into the factors associated with non-adherence or 
discontinuation of statins are important so as to optimise statin use towards achieving the intended cardiovascular benefits among older people with diabetes.

Keywords - Statin therapy, diabetes, adherence, discontinuation, geriatrics.

\section{Highlights}

- Over the last 10 years, there has been increased use of statins among Australians aged 65 years and over with diabetes.

- However, many older adults with diabetes in Australia who are prescribed statins do not adhere and discontinuation from therapy is high. 


\section{Background}

Type 2 diabetes is prevalent among older people due to a number of factors including increasing insulin resistance and pancreatic beta cell dysfunction. ${ }^{1}$ In the United States (US), over $25 \%$ of older adults have diabetes, ${ }^{2}$ and in Australia, approximately, half of individuals with diabetes are aged $\geq 65$ years. $^{3}$

People with diabetes are at high absolute risk of cardiovascular disease (CVD) and also experience high prevalence of co-morbidities such as dyslipidemia. ${ }^{4,5}$ Statins have been shown to reduce the risk of atherosclerotic CVD. ${ }^{6,7}$ Thus many people with diabetes benefit from statin therapy. The current American College of Cardiology/American Heart Association Guidelines recommend early and aggressive use of statins for lipid control among people with diabetes, with treatment targets informed by randomised clinical trials (RCTs). ${ }^{89}$ Within Australia, guidelines emphasise that cholesterol treatment should be integral component of management goals for patients with diabetes while noting 
that initiation of statin should also be informed by the assessment of absolute cardiovascular risk. ${ }^{10}$ However, compliance with clinical practice guidelines is often poor and statin prescribing for patients with diabetes have been shown in some studies to be sub-optimal. ${ }^{11}$

The benefits of statin therapy accrue over time, ${ }^{12}$ and optimal patient adherence is necessary. ${ }^{13,14}$ However, older patients with diabetes may find adherence to statin therapy challenging due to many reasons, including polypharmacy, ${ }^{15}$ increased susceptibility to adverse events,${ }^{16}$ and also as a result of declining executive and cognitive functioning. ${ }^{17}$ There is strong evidence linking statins with increased risk of diabetes. ${ }^{18}$ Furthermore, among persons with established diabetes, statin therapy has been associated with poor glycaemic control, ${ }^{19}$ which could contribute to increased discontinuation or poor adherence.

To date, limited studies have examined the patterns of long-term statin adherence and persistence among older adults with diabetes. Given the clinical importance of CVD prevention among patients with diabetes, understanding the dynamics of statin use is important to inform clinical practice. Therefore, we sought to assess the prevalence of statin use and determine long-term adherence and persistence among people aged e 65 years with diabetes.

\section{Methods}

\section{Study design and data sources}

We undertook a retrospective study using data from the Pharmaceutical Benefits Scheme (PBS) covering a random $10 \%$ sample of the Australian population. ${ }^{20}$

The PBS is funded by the Australian government and makes prescription medications available to Australians at subsidised costs. Contained in PBS data is information on medications dispensed (item 
number, name, quantity and date of dispensing), demographic information (sex, year of birth and year of death if applicable), persons' concessional status, prescriber information (identification number and specialty area), and details of state or territory of the pharmacy. The PBS datasets do not include diagnosis information nor laboratory test results (such as $\mathrm{HbA1c}$ ). The datasets were de-identified using unique identifiers for each person. For those who died, only year of death are captured in the dataset. Thus for the purposes of our analyses, we considered the month of death to be the month following their last dispensing of any medication in the dataset.

Statins were identified using the World Health Organisation's Anatomical Therapeutic Chemical Classification System [ATC] codes C10AA, C10BA, C10BX (supplemental Table S1). ${ }^{21}$ The statins included were fluvastatin, pravastatin, simvastatin, atorvastatin and rosuvastatin. Both plain and combination products were included. Cerivastatin was not included in this study as it was withdrawn from the Australian market in $2001,{ }^{22}$ nor pitavastatin because it is not listed on the PBS. ${ }^{23}$ Lovastatin is not available in Australia. The statins were grouped according to intensity based on their capacity to lower low-density lipoprotein cholesterol (LDL-C). As per their daily doses, statins that reduce LDL$\mathrm{C}$ by $<30 \%, 30-<50 \%$ and e $50 \%$ were categorised as low, moderate and high intensity, respectively (Supplemental Table S2). ${ }^{9,24}$

\section{Study population}

This study was carried out among adults aged e 65 years with diabetes who were dispensed medications included in the PBS datasets between 1 January 2007 and 31 December 2016. As no diagnosis records or laboratory results are available in the PBS datasets, diabetes status was ascertained via medication dispensation information (that is, any individual being dispensed medications belonging to ATC code A10 were deemed to have diabetes (Supplementary table S1). Additionally, prior to 2012, medications that were priced below the 'general patient co-payment 
threshold' were not captured in the PBS datasets. ${ }^{25}$ Therefore, as adopted in previous studies, ${ }^{25,26}$ we restricted our analysis to people with long-term concession status. Long-term concession status was defined by receipt of $\geq 90 \%$ of medications as a concession card holder. Previous studies have found that long-term concession individuals constitute more than $65 \%$ of all Australians receiving cardiovascular medications. ${ }^{25-27}$

\section{Outcomes}

The 1-year prevalence of statin use was computed by dividing the number of people with diabetes who redeemed at least one statin prescription during a calendar year by the total number of people with diabetes in the particular year. ${ }^{28}$

For the adherence and discontinuation analyses, we included only new statin users, defined as any person with diabetes being dispensed a statin with no statin dispensation in the previous 12 months. Additionally, only those who initiated statin treatment between 1 January 2007 and 31 March 2016 were included. The new user cohort was subsequently followed until death or 31 December 2016.

Adherence was assessed via the proportion of days covered (PDC) and calculated by dividing the number of days' supply by the number of days in the period. ${ }^{29}$ We assumed a dosage of one tablet per day because previous studies have demonstrated this to be the most commonly dispensed daily dose of statins. ${ }^{30}$ If there were overlapping refills, we assumed that the person would finish the current prescriptions before commencing the refill prescription. PDC was grouped into three categories: $<0.20,0.20-0.79 \%$ and e 0.80 , and patients were classified as non-adherent, partially adherent and adherent, respectively. ${ }^{31}$ We estimated cumulative adherence from 6 months to 9 years.

In Australia, a 30-day supply of statin is typically dispensed. Thus, we considered statin users to have discontinued when 90 or more days elapsed after the estimated end date of a statin prescription and no 
refill had been made. ${ }^{25,29}$ The time to discontinuation was determined as the period from the index date to the discontinuation (first 90-day gap) date.

\section{Statistical analysis}

Descriptive statistics were used to summarise the characteristics of the study population. The yearly prevalence of statin use was calculated for the overall diabetes population and stratified by age (65-74, $75-84$ and $\geq 85$ years) and sex. Relative changes in the prevalence of statin use were determined via Poisson regression modelling using 2006 as the reference year. Age and sex-adjusted rate ratios (aRR) and corresponding 95\% confidence intervals (CIs) were reported for the overall prevalence of statin use. We compared statin use as per gender by adjusting for age while differences across age were adjusted for sex. The likelihood of statin discontinuation was assessed via competing risk proportional hazards regression model, death being the competing risk. ${ }^{32}$ The variables included in the model were age, gender, statin type, statin intensity, prescriber type (general practitioner or other) and year of initiation.

In a sensitivity analyses, we varied the study population by relaxing the criteria to include all persons who received e $80 \%$ of medications under concession to assess the robustness of the prevalence estimates. The gap employed in the discontinuation analyses was also varied to 45 and 180 days. Statistical analysis was performed using STATA software (Stata/IC v14.1; StataCorp, College Station, TX, USA).

\section{Ethics}

This study was approved by the Monash University Human Research Ethics Committee. The Australian Government Department of Human Services also approved the research plan and the final manuscript.

\section{Results}


A total of 175,526 long-term concession older adults in the 10\% random PBS datasets were dispensed medications for diabetes in the period 2006-2016. The yearly numbers of people with diabetes more than doubled from 9,977 in 2006 to 22,618 in 2016 (Table 1). There were more females than males overall, although since 2010 , the gender distribution was even. The mean age remained generally stable across the years.

The prevalence of statin use increased consistently each year from $52.0 \%$ in 2006 to $71.2 \%$ in 2016 (aRR 1.37, 95\% CI 1.33-1.41). There was no gender difference in statin use (age-adjusted-RR for men compared to women; $0.99,95 \%$ CI $0.98-1.00)$. The likelihood of being dispensed statins decreased with age (sex-adjusted-RR for 75-84 years compared to 65-74 years: 0.97, 95\% CI 0.96-0.98; sexadjusted-RR for $85+$ years compared to $65-74$ years: $0.77,95 \%$ CI $0.75-0.78)$. The overall patterns in the prevalence of statin use did not change when the sample criteria was modified to include all persons with diabetes who received $\geq 80 \%$ of medications under concession (Supplemental Figures S1).

Among older adults with diabetes who were prescribed statins, a cohort of 7,400 persons who started statin treatment between January 2007 and March 2016 were assembled for the longitudinal analyses. The mean age of this cohort was 72.9 (SD 6.6) years, and $46.2 \%$ were women. Of the cohort, $47.5 \%$ were initiated by GPs. Also, 3.4\%, 70.2\% and 26.4\% commenced with low, moderate and high intensity statins, respectively. By individual statin, $12.5 \%, 2.2 \%$, 47.7 and $37.6 \%$ were initiated on simvastatin, atorvastatin, rosuvastatin or other (fluvastatin or pravastatin), respectively. The mean follow-up period for the cohort was 4.9 (SD 2.7) years, and $18.7 \%(n=1,382)$ of the cohort died by the end of the study period.

The mean PDC decreased from 0.69 (SD 0.32) at 6 months to 0.56 (SD 0.31) at 9 years. The proportion of statin users who were adherent (PDC e 0.80 ) declined from $54.0 \%$ at 6 months to $30.7 \%$ 
at 9 years. Conversely, the proportion of patients with very low PDC $(<0.20)$ increased from $16.8 \%$ at 6 months to $19.7 \%$ at 9 years (Figure 1).

Of the new statin users, more than two-thirds $(66.8 \%, n=4942)$ discontinued during the follow-up based on the 90-day gap criteria. The overall discontinuation rate was 29.1 per 100 person-years. At 6 months, 1 year and 2 years, 27.2\%, 42.7\% and 54.1\% had discontinued, respectively (Figure 2). There was no gender difference in discontinuation patterns (hazard ratio [HR] for males compared to females, 0.94 (95\% CI 0.89-1.01), nor did the discontinuation appear to differ with age (HR for 75-84 years and $85+$ years 1.03 (95\% CI 0.97-1.10) and 0.91 (95\% CI 0.81-1.02), respectively, compared to 65-74 years). However, statin users who were initiated by GPs were more likely to discontinue than those initiated by other prescribers (HR 1.15, 95\% CI 1.08-1.23).

The proportion of patients that discontinued when 45 and 180 permissible days were applied was $79.4 \%$ $(n=5,873)$ and $40.4 \%(n=4,044)$, respectively. For the 45-day gap, the overall discontinuation rate was 47.5 per 100 person-years, and $41.0 \%, 55.8 \%$ and $66.8 \%$ had discontinued after 6 months, 1 year and 2 years, respectively. With a 180-day permissible gap, the overall discontinuation rate was 18.7 per 100 person-years, and $28.3 \%$ and $41.5 \%$ discontinued after 1 year and 2 years, respectively.

\section{Discussion}

We found increased use of statins among older adults with diabetes over the last decade. Compared to 2007, older Australians with diabetes in 2016 were 37\% more likely to be dispensed statins. These trends are consistent with the patterns of statin use reported among cohort of patients with diabetes in other developed countries, ${ }^{33}$ and among general populations of older adults. ${ }^{34,35}$ For persons with diabetes who are at increased risk of CVD, guidelines have increasingly emphasised the importance of

statin treatment. ${ }^{8,9,36}$ In particular, current clinical guidelines recommend statins for all patients with diabetes aged $\geq 40$ years with or without CVD. ${ }^{8}$ However, despite the increase observed, nearly $30 \%$ 
of older Australians with diabetes were not prescribed statins in 2016 and this warrants further investigation to identify contributory factors so as to optimise statin use in this population at high risk of CVD progression and death. ${ }^{37}$

Statin use was lower among people aged $\geq 75$ years, which may largely reflect the growing concern/ debate around the benefits and harms of statin therapy in this population. ${ }^{38}$

We observed poor statin adherence among the older people with diabetes. The proportion of people who were adherent declined sharply within the first 6 months, before reaching a slower rate of decline over time. This observation is consistent with data from other longitudinal studies. ${ }^{39}$ In a recent metaanalysis that pooled data from more than 3 million older statin users from over 40 countries, it was noted that the proportion adherent (PDC/medication possession ratio [MPR] e 0.80 ) declined from $60 \%$ at 6 months to just $28 \%$ at 10 years. ${ }^{40}$ These patterns highlight the need for support with adherence at commencement of treatment and for a longer period as part of regular medication management plans. ${ }^{41}$ The need for increased efforts at improving adherence is further supported by increasing evidence of adverse clinical outcomes as a consequence of poor adherence. For example, in comparison to patients with diabetes who are adherent to statin therapy, those who are non-adherent are about 1.2-5.3 times more likely to develop CVD and 1.3-3.5 times more likely to die from it. ${ }^{42}$

Our analysis also showed that among older Australians with diabetes who commenced statin therapy, more than $66 \%$ discontinued, including over $40 \%$ who did so within the first year. This discontinuation is comparable to previously reported rates in the Netherlands. ${ }^{43}$ However, some studies of older populations have reported slightly different statin persistence rates, a trend that is often attributed to the permissible gap applied and the length of follow-up. ${ }^{44}$ For example, Abughosh and colleagues reported a statin discontinuation rate of 39.0\% among older Americans when applying a permissible gap of 180 days ${ }^{45}$ whereas a discontinuation rate of $>80 \%$ was reported for Italian 
patients based on a permissible gap of 30 -days. ${ }^{46}$ Indeed, our sensitivity analyses showed that the level of discontinuation was dictated by the permissible gap applied, suggesting that the use of shorter gaps may lead to over-estimation of discontinuation rates. Regardless, the overall discontinuation is high, which needs to be addressed as evidence suggests that statin cessation in patients with diabetes is associated with adverse clinical otucomes. For example, $79 \%$ of persons with diabetes who had stopped statin treatment after having achieved LDL-C targets experienced relapsed dyslipidaemia compared to $3 \%$ of those who maintained treatment. ${ }^{47}$ Persons with diabetes who discontinue statins are also up to five times more likely to die than those persisting with treatment. ${ }^{42}$

We also found that people who were initiated on statins by GPs were about $13 \%$ more likely to discontinue than those initiated by others including specialists. Although we had no clinical data for our analyses, we speculate this trend to be likely as a result of patients initiated by non-GPs to be likely higher risk patients, who may perceive grater gains from statin therapy and may be more committed to treatment. ${ }^{25,40}$

Our results reiterate the need for interventions to improve statin adherence and persistence among older people with diabetes for whom statins are deemed to be clinically essential. A recent study suggested that real-time medication monitoring that is combined with short message service (SMS) reminders was effective at improving refill adherence among patients with diabetes. ${ }^{48}$ Due to the likelihood of polypharmacy among older people, ${ }^{15}$ measures to reduce regimen complexity are also necessary. ${ }^{49}$ Furthermore, interventions that seek to improve patient education or offer extended supervisory health services, ${ }^{50}$ have been noted to enhance compliance with the best outcomes likely to be achieved by a combination of multi-faceted interventions. ${ }^{41,51}$

Our study has important strengths and limitations. To our knowledge, this is the first study to describe in detail statin utilisation and long-term adherence and discontinuation patterns among older adults 
with diabetes in Australia. Our analysis was based on a large sample of data from the PBS, which has been considered to be reliable for pharmaceutical policy and health services research in Australia. ${ }^{20}$

A main limitation of our study is that we had no information on the underlying reasons for why patients were non-adherent or discontinued statins. It is possible that some discontinuation may have been due to adverse events or directed by clinicians. Furthermore, given that we did not have access to hospitalisation records, we may have over-estimated the treatment gap or under-estimated adherence among people who were hospitalised during the follow up. Additionally, our analysis was based only on medication acquisition data, and hence we were unable to verify if people actually took the statins. Our study population was also selected on the basis of diabetes medication use and we may have excluded any people with diabetes being managed with diet alone. We were also unable to stratify our results by presence or absence of symptomatic cardiovascular events, which may be associated with different patterns of statin use and adherence or persistence. ${ }^{40}$ Lastly, we didn't investigate whether specific statins or intensity were associated with higher or lower rates of adherence or persistence, nor socio-demographic or lifestyle factors. However, a recent meta-analysis involving more than 1.8 million older statin users in 13 countries found no significant difference in adherence or persistence according to statin type or intensity. ${ }^{52}$

\section{Conclusions}

The proportion of older adults with diabetes using statins has increased over the last decade. However, adherence is poor and discontinuation is high. Further investigations into the factors associated with non-adherence or discontinuation of statins are important so as to optimise statin use to achieve the intended cardiovascular benefits among older people with diabetes. 


\section{Acknowledgement}

The study authors are grateful to the Australian Government Department of Human Services for supplying the PBS data.

\section{Funding}

R.O. is supported by a Monash Graduate Scholarship and Monash International Postgraduate Research Scholarship for his doctoral studies. J.I. is funded by National Health and Medical Research Council Early Career Fellowship. S.Z. is funded by a National Health and Medical Research Council Senior Research Fellowship. No other funding has been required to undertake this work.

\section{Conflict of Interest}


SZ reports past participation in advisory boards and/or receiving honoraria from AstraZeneca/BristolMyers Squibb Australia; Janssen-Cilag; Merck, Sharp, and Dohme (Australia); Novartis Australia; Novo Nordisk; Sanofi and Servier Laboratories for work unrelated to this study. DL reports past participation in advisory boards and/or receiving honoraria from Abbvie, Astellas, AstraZeneca, Bristol-Myers Squibb, Novartis, Pfizer, Sanofi and Shire for work unrelated to this study.

\section{References}

1. Cerf ME. Beta cell dysfunction and insulin resistance. Frontiers in endocrinology. 2013;4:37.

2. Kirkman MS, Briscoe VJ, Clark N, et al. Diabetes in older adults. Diabetes care. Dec 2012;35(12):2650-2664.

3. (NDSS) NDSS. Older People. 2017; https://www.ndss.com.au/older-people. Accessed January 082018 .

This article is protected by copyright. All rights reserved. 
4. Leon BM, Maddox TM. Diabetes and cardiovascular disease: Epidemiology, biological mechanisms, treatment recommendations and future research. World journal of diabetes. Oct 10 2015;6(13):1246-1258.

5. Mooradian AD. Dyslipidemia in type 2 diabetes mellitus. Nature clinical practice. Endocrinology \& metabolism. Mar 2009;5(3):150-159.

6. Naci H, Brugts J, Ades T. Comparative tolerability and harms of individual statins: a studylevel network meta-analysis of 246955 participants from 135 randomized, controlled trials. Circulation. Cardiovascular quality and outcomes. Jul 2013;6(4):390-399.

7. Taylor F, Huffman MD, Macedo AF, et al. Statins for the primary prevention of cardiovascular disease. The Cochrane database of systematic reviews. Jan 31 2013(1):CD004816.

8. Standards of Medical Care in Diabetes-2016: Summary of Revisions. Diabetes care. Jan 2016;39 Suppl 1:S4-5.

9. Stone NJ, Robinson JG, Lichtenstein AH, et al. 2013 ACC/AHA guideline on the treatment of blood cholesterol to reduce atherosclerotic cardiovascular risk in adults: a report of the American College of Cardiology/American Heart Association Task Force on Practice Guidelines. Journal of the American College of Cardiology. Jul 01 2014;63(25 Pt B):28892934.

10. The Royal Australian College of General Practitioners and Diabetes Australia. General practice management of type 2 diabetes - 2014-15. Melbourne: The Royal Australian College of General Practitioners; 2014.

11. Yong TY, Phillipov G, Phillips PJ. Management outcomes of patients with type 2 diabetes: targeting the 10-year absolute risk of coronary heart disease. The Medical journal of Australia. Jun 18 2007;186(12):622-624. 
12. Collins R, Reith C, Emberson J, et al. Interpretation of the evidence for the efficacy and safety of statin therapy. Lancet. Nov 19 2016;388(10059):2532-2561.

13. Choudhry NK, Glynn RJ, Avorn J, et al. Untangling the relationship between medication adherence and post-myocardial infarction outcomes: medication adherence and clinical outcomes. Am Heart J. Jan 2014;167(1):51-58 e55.

14. Chowdhury R, Khan H, Heydon E, et al. Adherence to cardiovascular therapy: a metaanalysis of prevalence and clinical consequences. Eur Heart J. Oct 2013;34(38):2940-2948.

15. Noale M, Veronese N, Cavallo Perin P, et al. Polypharmacy in elderly patients with type 2 diabetes receiving oral antidiabetic treatment. Acta diabetologica. Apr 2016;53(2):323-330.

16. Wilmot KA, Khan A, Krishnan S, Eapen DJ, Sperling L. Statins in the elderly: a patientfocused approach. Clinical cardiology. Jan 2015;38(1):56-61.

17. Deary IJ, Corley J, Gow AJ, et al. Age-associated cognitive decline. British medical bulletin. 2009;92:135-152.

18. Crandall JP, Mather K, Rajpathak SN, et al. Statin use and risk of developing diabetes: results from the Diabetes Prevention Program. BMJ Open Diabetes Res Care. 2017;5(1):e000438.

19. Bardini G, Giannini S, Rotella CM, Pala L, Cresci B, Mannucci E. Lower and higher-potency statins on glycemic control in type 2 diabetes: A retrospective cohort study. Diabetes Res Clin Pract. Oct 2016;120:104-110.

20. Mellish L, Karanges EA, Litchfield MJ, et al. The Australian Pharmaceutical Benefits Scheme data collection: a practical guide for researchers. BMC Res Notes. Nov 2 2015;8:634.

21. WHO Collaborating Centre for Drug Statistics Methodology. Guidelines for ATC classification and DDD assignment Oslo2016.

22. Furberg CD, Pitt B. Withdrawal of cerivastatin from the world market. Current controlled trials in cardiovascular medicine. 2001;2(5):205-207. 
23. Department of Health. July 2012 PBAC Outcomes - 1st time decisions not to recommend. 2012; https://www.pbs.gov.au/pbs/industry/listing/elements/pbac-meetings/pbacoutcomes/2012-07/1st-time-decisions.

24. Robson J. Lipid modification: cardiovascular risk assessment and the modification of blood lipids for the primary and secondary prevention of cardiovascular disease. Heart. Oct 2008;94(10):1331-1332.

25. Simons LA, Ortiz M, Calcino G. Long term persistence with statin therapy -- experience in Australia 2006-2010. Australian family physician. May 2011;40(5):319-322.

26. Simons LA, Chung E. Are high coronary risk patients missing out on lipid-lowering drugs in Australia? The Medical journal of Australia. Aug 18 2014;201(4):213-216.

27. Simons LA, Ortiz M, Calcino G. Persistence with antihypertensive medication: Australiawide experience, 2004-2006. The Medical journal of Australia. Feb 18 2008;188(4):224-227.

28. Geleedst-De Vooght M, Maitland-van der Zee AH, Schalekamp T, Mantel-Teeuwisse A, Jansen P. Statin prescribing in the elderly in the Netherlands: a pharmacy database time trend study. Drugs \& aging. Jul 01 2010;27(7):589-596.

29. Cramer JA, Roy A, Burrell A, et al. Medication compliance and persistence: terminology and definitions. Value in health : the journal of the International Society for Pharmacoeconomics and Outcomes Research. Jan-Feb 2008;11(1):44-47.

30. Romppainen T, Rikala M, Aarnio E, Korhonen MJ, Saastamoinen LK, Huupponen R. Measurement of statin exposure in the absence of information on prescribed doses. European journal of clinical pharmacology. Oct 2014;70(10):1275-1276.

31. Karve S, Cleves MA, Helm M, Hudson TJ, West DS, Martin BC. Good and poor adherence: optimal cut-point for adherence measures using administrative claims data. Current medical research and opinion. Sep 2009;25(9):2303-2310. 
32. Berry SD, Ngo L, Samelson EJ, Kiel DP. Competing risk of death: an important consideration in studies of older adults. Journal of the American Geriatrics Society. Apr 2010;58(4):783787.

33. Brennan MB, Huang ES, Lobo JM, et al. Longitudinal trends and predictors of statin use among patients with diabetes. Journal of diabetes and its complications. Sep 252017.

34. Salami JA, Warraich H, Valero-Elizondo J, et al. National Trends in Statin Use and Expenditures in the US Adult Population From 2002 to 2013: Insights From the Medical Expenditure Panel Survey. JAMA cardiology. Jan 01 2017;2(1):56-65.

35. Minard LV, Corkum A, Sketris I, Fisher J, Zhang Y, Saleh A. Trends in Statin Use in Seniors 1999 to 2013: Time Series Analysis. PloS one. 2016;11(7):e0158608.

36. Kamari Y, Bitzur R, Cohen H, Shaish A, Harats D. Should all diabetic patients be treated with a statin? Diabetes care. Nov 2009;32 Suppl 2:S378-383.

37. American Heart Association. Cardiovascular Disease \& Diabetes. 2017; http://www.heart.org/HEARTORG/Conditions/More/Diabetes/WhyDiabetesMatters/Cardiova scular-Disease-Diabetes_UCM_313865_Article.jsp/\#.WiC1SIWWbIU. Accessed December 012017.

38. Gurwitz JH, Go AS, Fortmann SP. Statins for Primary Prevention in Older Adults: Uncertainty and the Need for More Evidence. Jama. Nov 15 2016;316(19):1971-1972.

39. Donnelly LA, Doney AS, Morris AD, Palmer CN, Donnan PT. Long-term adherence to statin treatment in diabetes. Diabetic medicine : a journal of the British Diabetic Association. Jul 2008;25(7):850-855.

40. Ofori-Asenso R, Jahku A, Zomer E, et al. Adherence and Persistence among Statin Users aged 65 years and over: A Systematic Review and Meta-analysis. 2017.

This article is protected by copyright. All rights reserved. 
41. Maningat $\mathrm{P}$, Gordon BR, Breslow JL. How do we improve patient compliance and adherence to long-term statin therapy? Current atherosclerosis reports. Jan 2013;15(1):291.

42. De Vera MA, Bhole V, Burns LC, Lacaille D. Impact of statin adherence on cardiovascular disease and mortality outcomes: a systematic review. British journal of clinical pharmacology. Oct 2014;78(4):684-698.

43. Lamberts EJ, Nijpels G, Welschen LM, et al. Discontinuation of statins among patients with type 2 diabetes. Diabetes/metabolism research and reviews. Mar 2012;28(3):241-245.

44. Geers HC, Bouvy ML, Heerdink ER. Estimates of statin discontinuation rates are influenced by exposure and outcome definitions. The Annals of pharmacotherapy. May 2011;45(5):576581.

45. Abughosh SM, Kogut SJ, Andrade SE, Larrat P, Gurwitz JH. Persistence with lipid-lowering therapy: influence of the type of lipid-lowering agent and drug benefit plan option in elderly patients. Journal of managed care pharmacy: JMCP. Sep-Oct 2004;10(5):404-411.

46. Abraha I, Montedori A, Stracci F, Rossi M, Romagnoli C. Statin compliance in the Umbrian population. European journal of clinical pharmacology. Nov 2003;59(8-9):659-661.

47. Lee SH, Kwon HS, Park YM, et al. Statin Discontinuation after Achieving a Target Low Density Lipoprotein Cholesterol Level in Type 2 Diabetic Patients without Cardiovascular Disease: A Randomized Controlled Study. Diabetes \& metabolism journal. Feb 2014;38(1):64-73.

48. Vervloet M, van Dijk L, de Bakker DH, et al. Short- and long-term effects of real-time medication monitoring with short message service (SMS) reminders for missed doses on the refill adherence of people with Type 2 diabetes: evidence from a randomized controlled trial. Diabetic medicine : a journal of the British Diabetic Association. Jul 2014;31(7):821-828. 
49. Choudhry NK, Fischer MA, Avorn J, et al. The implications of therapeutic complexity on adherence to cardiovascular medications. Archives of internal medicine. May 9 2011;171(9):814-822.

50. Schedlbauer A, Davies P, Fahey T. Interventions to improve adherence to lipid lowering medication. The Cochrane database of systematic reviews. Mar 17 2010(3):CD004371.

51. Phan K, Gomez YH, Elbaz L, Daskalopoulou SS. Statin treatment non-adherence and discontinuation: clinical implications and potential solutions. Current pharmaceutical design. 2014;20(40):6314-6324.

52. Ofori-Asenso R, Jakhu A, Curtis AJ, et al. A Systematic Review and Meta-analysis of the Factors Associated With Nonadherence and Discontinuation of Statins Among People Aged >/=65 Years. J Gerontol A Biol Sci Med Sci. Jan 192018.

\section{Legends}

Fig 1: Proportion of older adults with diabetes who were adherent (PDC e 0.80), partially adherent (PDC 0.20-0.79) or non-adherent $(\mathrm{PDC}<0.20)$ at different follow up periods.

Fig 2: Cumulative incidence function curve of the probability of discontinuimng statin therapy in a cohort of older adults with diabetes in which stopping was defined as 45, 90 and 180 or more days respectively without statin medication. 
This article is protected by copyright. All rights reserved. 


\section{Supplementary Material}

Table S1: ATC codes used to identify people with diabetes and statin scripts

ATC code $\quad$ Medication details

Diabetes Medication

A10A insulins and analogues

A10B blood glucose lowering drugs, excl. insulins

This article is protected by copyright. All rights reserved. 


\begin{tabular}{ll}
\hline A10X & other drugs used in diabetes \\
\hline \multicolumn{2}{l}{ Statins (HMG-CoA reductase inhibitors) } \\
\hline C10AA01 & Simvastatin \\
\hline C10AA03 & Pravastatin \\
\hline C10AA04 & Fluvastatin \\
\hline C10AA05 & Atorvastatin \\
\hline C10AA07 & Rosuvastatin \\
\hline C10BA & Statins + other lipid modifying agents \\
\hline C10BX & Statin + other combinations \\
\hline
\end{tabular}

Table S2: Classification of statins according to intensity

This article is protected by copyright. All rights reserved. 


\begin{tabular}{|c|c|c|}
\hline \multirow[t]{4}{*}{ Low intensity } & Daily dose lowers LDL-C by & Simvastatin 10 mg \\
\hline & \multirow[t]{3}{*}{$<30 \%$, on average } & Pravastatin $10-20 \mathrm{mg}$ \\
\hline & & Fluvastatin $20-40 \mathrm{mg}$ \\
\hline & & Lovastatin $20 \mathrm{mg}$ \\
\hline \multirow[t]{6}{*}{ Medium intensity } & \multirow[t]{6}{*}{ Daily dose lowers LDL-C by } & Atorvastatin $10-20 \mathrm{mg}$ \\
\hline & & Rosuvastatin 5-10 mg \\
\hline & & Simvastatin $20-40 \mathrm{mg}$ \\
\hline & & Lovastatin $40 \mathrm{mg}$ \\
\hline & & Fluvastatin $80 \mathrm{mg}$ \\
\hline & & Pravastatin $40-80 \mathrm{mg}$ \\
\hline \multirow[t]{3}{*}{ High intensity } & \multirow[t]{3}{*}{ Daily dose lowers LDL-C by } & Simvastatin $80 \mathrm{mg}$ \\
\hline & & Rosuvastatin $20-40 \mathrm{mg}$ \\
\hline & & Atorvastatin $40-80 \mathrm{mg}$ \\
\hline
\end{tabular}


Figure S1: Trends in the prevalence of statin use among older adults with diabetes

whereby the analysis is restricted to all persons who received $\geq 80 \%$ of medications under concession

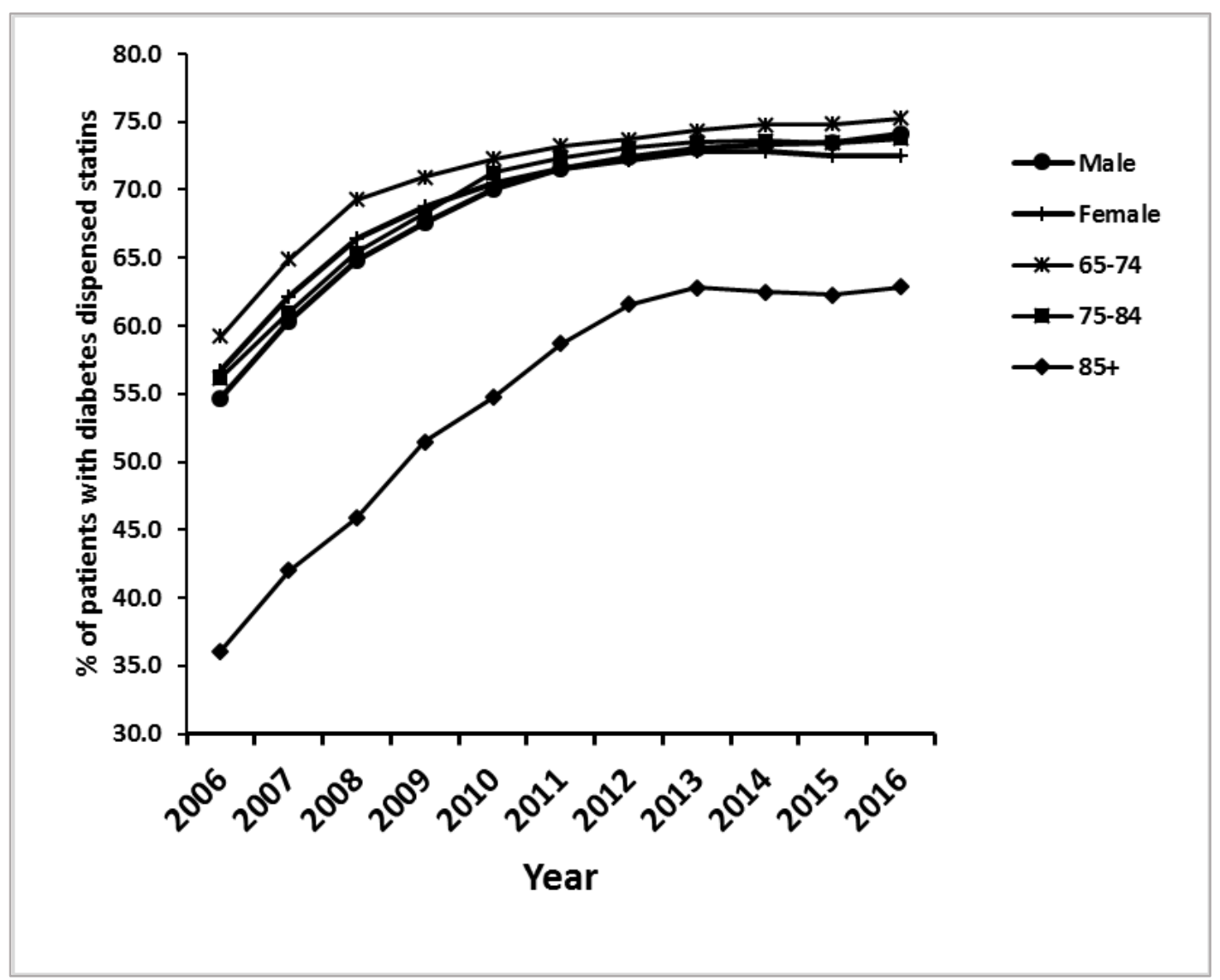




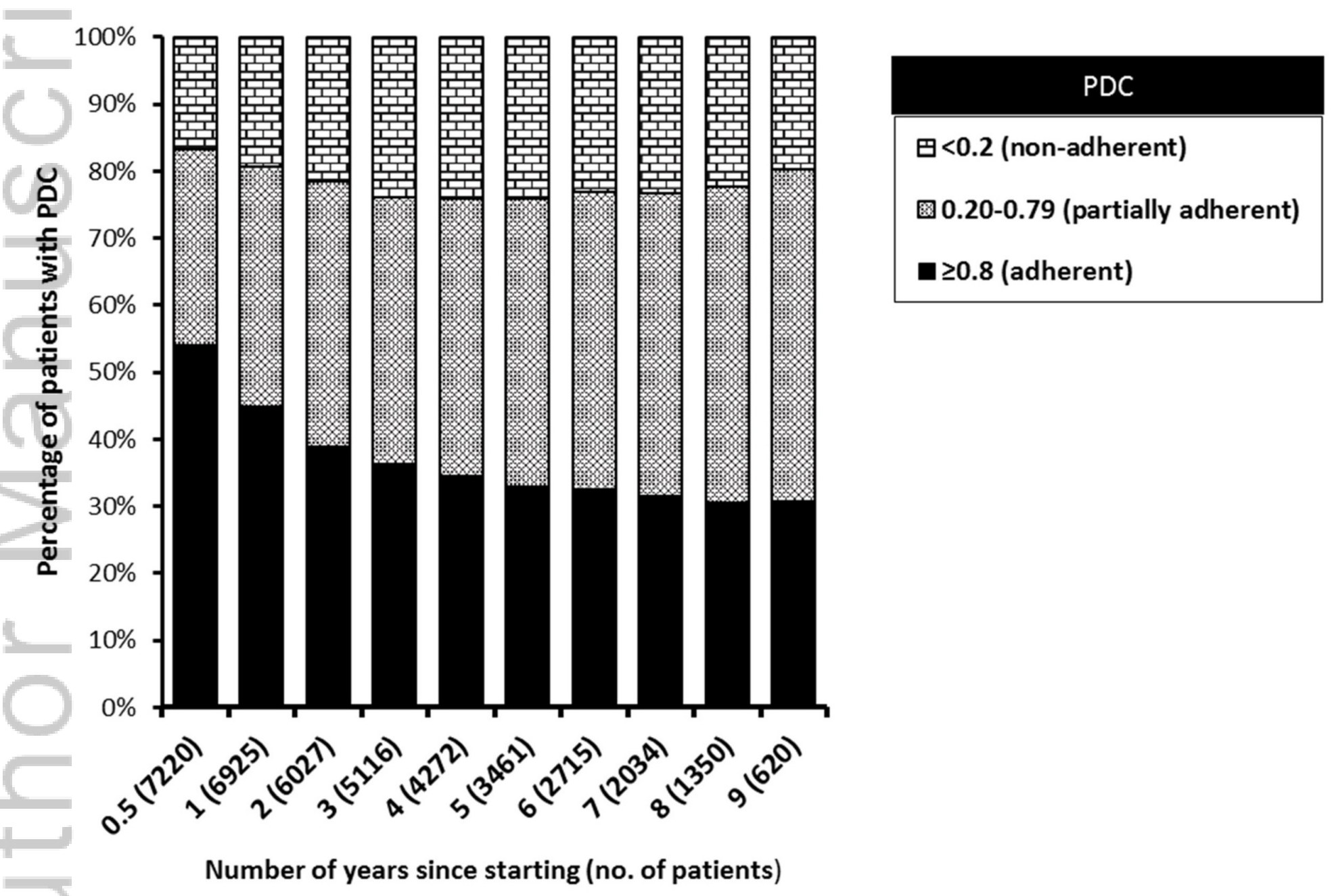

JDB_12769_fig1_diabetes.jpg 


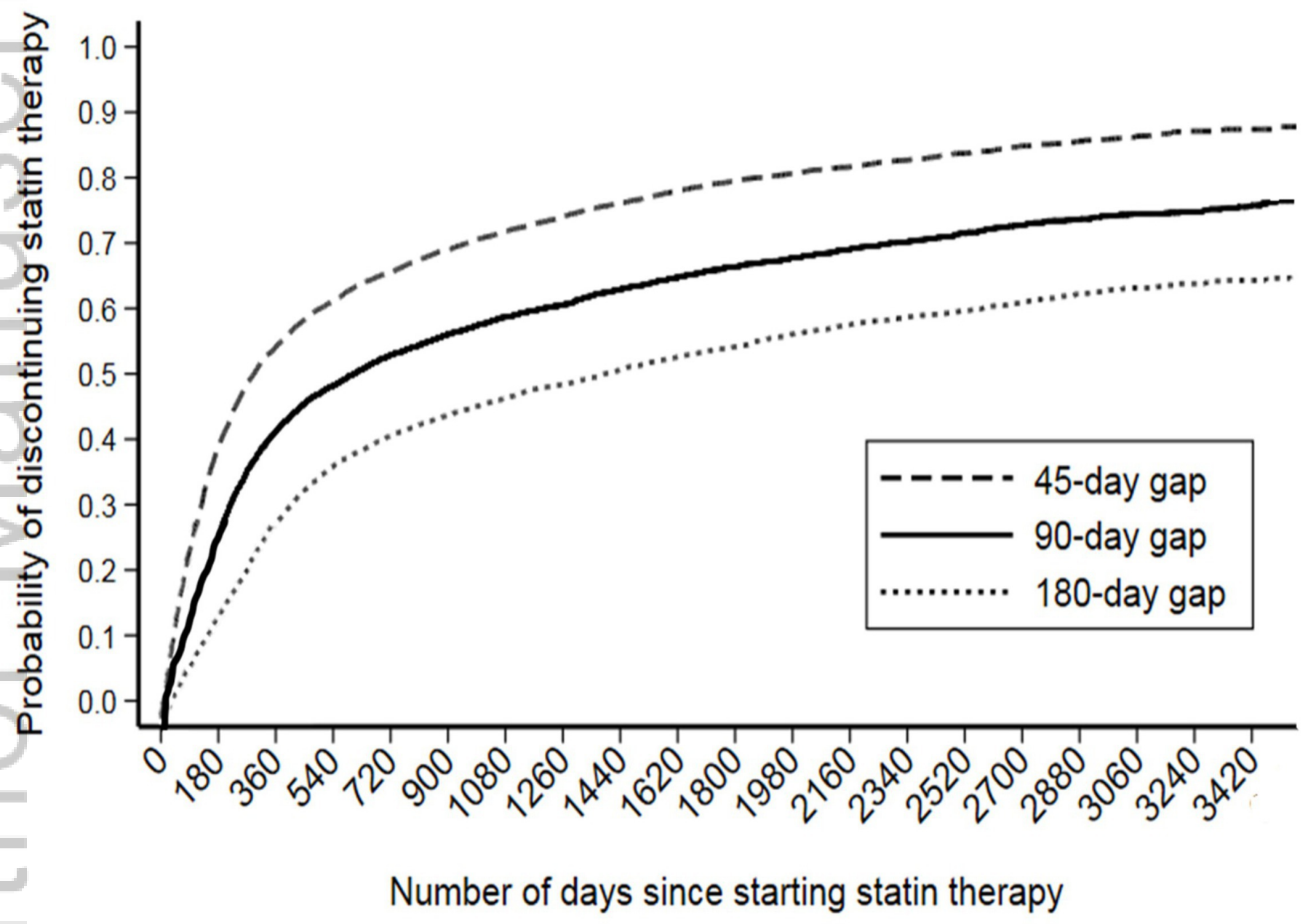

JDB_12769_fig2_diabetes.jpg 
Table 1: Characteristics and prevalence of statin use among older adults with diabetes from 2006 to 2016

\begin{tabular}{|c|c|c|c|c|c|c|c|c|c|c|c|c|}
\hline \multirow{2}{*}{ Characteristics } & \multicolumn{11}{|c|}{ Year } & \multirow[b]{2}{*}{ p-value } \\
\hline & 2006 & 2007 & 2008 & 2009 & 2010 & 2011 & 2012 & 2013 & 2014 & 2015 & 2016 & \\
\hline No. patients with diabetes ${ }^{*}$ & 9,977 & 10,566 & 11,633 & 12,855 & 14,114 & 15,733 & 17,392 & 18,896 & 20,213 & 21,529 & 22,618 & \\
\hline \multicolumn{13}{|l|}{ Demographics } \\
\hline $\begin{array}{l}\text { Mean age (S.D), yrs } \\
\text { Age group (\%) }\end{array}$ & $75.0(7.6)$ & $74.7(7.4)$ & $74.6(7.3)$ & $74.5(7.2)$ & $74.5(7.1)$ & $74.4(7.1)$ & $74.5(7.1)$ & $74.4(7.0)$ & $74.6(7.0)$ & $74.7(7.0)$ & $74.9(7.0)$ & 0.078 \\
\hline $65-74$ & 52.9 & 54.5 & 55.3 & 56.1 & 56.0 & 56.2 & 56.1 & 56.2 & 55.4 & 54.7 & 53.1 & \\
\hline $75-84$ & 35.9 & 35.3 & 34.9 & 34.3 & 34.4 & 34.5 & 34.2 & 33.9 & 34.3 & 34.8 & 35.9 & \\
\hline$\geq 85$ & 11.2 & 10.3 & 9.8 & 9.6 & 9.6 & 9.3 & 9.7 & 9.9 & 10.3 & 10.5 & 11.0 & $<0.01$ \\
\hline \multicolumn{13}{|l|}{$\operatorname{Sex}(\%)$} \\
\hline Male & 46.8 & 47.8 & 48.5 & 49.0 & 49.7 & 50.0 & 50.2 & 50.2 & 50.2 & 50.2 & 50.0 & \\
\hline Female & 53.2 & 52.2 & 51.5 & 51.0 & 50.3 & 50.0 & 49.8 & 49.8 & 49.8 & 49.8 & 50.0 & $<0.01$ \\
\hline \multicolumn{13}{|c|}{ Prevalence of statin use (\%) } \\
\hline All & 52.0 & 57.5 & 62.4 & 64.9 & 67.1 & 68.4 & 69.3 & 69.9 & 70.2 & 70.5 & 71.2 & \\
\hline Male & 51.2 & 56.6 & 61.4 & 64.3 & 66.7 & 68.1 & 69.1 & 69.6 & 70.2 & 70.5 & 71.6 & \\
\hline Female & 52.8 & 58.3 & 63.3 & 65.5 & 67.5 & 68.7 & 69.5 & 70.3 & 70.3 & 70.4 & 70.8 & \\
\hline $65-74$ & 56.2 & 61.8 & 66.4 & 68.1 & 69.2 & 69.9 & 70.6 & 71.4 & 72.0 & 72.1 & 73.1 & \\
\hline $75-84$ & 52.4 & 57.2 & 62.2 & 65.0 & 68.3 & 69.7 & 70.4 & 70.4 & 70.6 & 70.9 & 71.4 & \\
\hline$\geq 85$ & 31.2 & 35.6 & 40.5 & 46.2 & 50.9 & 54.4 & 58.0 & 60.1 & 59.7 & 60.4 & 60.9 & \\
\hline $\begin{array}{l}\text { aRR }(95 \% \mathrm{CI})^{\ddagger} \text { for overall } \\
\text { prevalence of statin use }\end{array}$ & & $\begin{array}{l}1.10 \\
(1.06- \\
1.14)\end{array}$ & $\begin{array}{l}1.20 \\
(1.15- \\
1.24)\end{array}$ & $\begin{array}{l}1.25 \\
(1.20- \\
1.29)\end{array}$ & $\begin{array}{l}1.29 \\
(1.24- \\
1.33)\end{array}$ & $\begin{array}{l}1.31 \\
(1.27- \\
1.36)\end{array}$ & $\begin{array}{l}1.33 \\
(1.29- \\
1.37)\end{array}$ & $\begin{array}{l}1.34 \\
(1.30- \\
1.38)\end{array}$ & $\begin{array}{l}1.35 \\
(1.31- \\
1.39)\end{array}$ & $\begin{array}{l}1.35 \\
(1.31- \\
1.40)\end{array}$ & $\begin{array}{l}1.37 \\
(1.33- \\
1.41)\end{array}$ & \\
\hline
\end{tabular}

*analyses have been restricted to long-term concession patients; ${ }^{\ddagger} 2006$ was used as the reference year. ${ }^{\dagger}$ Proportions assessed via Pearson $\mathrm{x}^{2}$-test and means tested via one-way ANOVA. ARR=age-and-sex-adjusted rate ratio; $\mathrm{S} . \mathrm{D}=$ standard deviation; $\mathrm{CI}=$ confidence interval

This article is protected by copyright. All rights reserved. 


\section{Patterns of Statin Use and Long-term Adherence and Persistence among Older Adults with}

Diabetes

Running title: Statin use in older Australians with diabetes.

Richard OFORI-ASENSO ${ }^{1,2,3}$; Jenni LLOMÄKII ${ }^{4,5}$; Mark TACEY ${ }^{1}$; Ella ZOMER ${ }^{1}$; Andrea J

CURTIS $^{3}$; J Simon BELL ${ }^{4,5,6}$; Sophia ZOUNGAS 3 ; Danny LIEW ${ }^{1 *}$

${ }^{1}$ Centre of Cardiovascular Research and Education in Therapeutics, Department of Epidemiology and Preventive Medicine, Monash University, Melbourne, Australia;

${ }^{2}$ Epidemiological Modelling Unit, Department of Epidemiology and Preventive Medicine, Monash University, Melbourne, Australia

${ }^{3}$ Division of Metabolism, Ageing and Genomics, Department of Epidemiology and Preventive Medicine, Monash University, Melbourne, Australia.

${ }^{4}$ Centre for Medicine Use and Safety, Faculty of Pharmacy and Pharmaceutical Science, Monash University, Melbourne, Australia.

${ }^{5}$ Department of Epidemiology and Preventive Medicine, Monash University, Melbourne, Australia.

${ }^{6}$ School of Pharmacy and Medical Sciences, University of South Australia, Adelaide, Australia.

\section{*Correspondence to:}

Professor Danny Liew

Department of Epidemiology and Preventive Medicine

Monash University

99 Commercial Road,

'Melbourne, Australia

VIC 3004

Tel: $+61-3990-30759$

danny.liew@monash.edu

Word count (main text): 3154

Number of figures: 2

Number of tables: 1

This article is protected by copyright. All rights reserved. 


\section{University Library}

\section{- M M N E R VA A gateway to Melbourne's research publications}

Minerva Access is the Institutional Repository of The University of Melbourne

Author/s:

Ofori-Asenso, R;llomaki, J;Tacey, M;Zomer, E;Curtis, AJ;Bell, JS;Zoungas, S;Liew, D

Title:

Patterns of statin use and long-term adherence and persistence among older adults with diabetes

Date:

2018-09-01

Citation:

Ofori-Asenso, R., llomaki, J., Tacey, M., Zomer, E., Curtis, A. J., Bell, J. S., Zoungas, S. \& Liew, D. (2018). Patterns of statin use and long-term adherence and persistence among older adults with diabetes. JOURNAL OF DIABETES, 10 (9), pp.699-707. https:// doi.org/10.1111/1753-0407.12769.

Persistent Link:

http://hdl.handle.net/11343/283971 